Seção Temática: Balanço do Fundeb

Volume 10 - $2020 \mid$ n. 22

\title{
Contribuições para um Balanço do Fundeb: redistribuição dos recursos, despesas com remuneração e vínculo de trabalho docente
}

\author{
Márcia Aparecida Jacomini \\ Universidade Federal de São Paulo (UNIFESP), Guarulhos/SP - Brasil \\ Marcos Edgar Bassi \\ Universidade Federal de Santa Catarina (UFSC), Florianópolis/SC - Brasil \\ Maria Dilnéia Espíndola Fernandes \\ Universidade Federal de Mato Grosso do Sul (UFMS), Campo Grande/MS - Brasil \\ Rosana Maria Gemaque Rolim \\ Universidade Federal do Pará (UFPA), Belém/PA - Brasil \\ Rubens Barbosa de Camargo \\ Universidade de São Paulo (USP), São Paulo/SP - Brasil
}

\section{Resumo}

Neste artigo são investigados efeitos do Fundo de Manutenção e Desenvolvimento da Educação Básica e de Valorização dos Profissionais da Educação (Fundeb) nas condições do trabalho docente. Para tal, foram analisadas as dimensões: municipalização de matrículas e de recursos do fundo; valor aluno/ano e o Piso Salarial Profissional Nacional (PSPN); uso dos recursos do Fundeb para pagamento dos profissionais da educação nas redes estaduais; tipos de vínculos empregatícios de professores nas redes estaduais. Trabalhou-se com a legislação educacional, dados educacionais e financeiros disponibilizados pela União e pelo Instituto de Estudos e Pesquisas Educacionais Anísio Teixeira. Constatou-se que o Fundeb, nas dimensões analisadas, promoveu alterações substantivas na política educacional brasileira da educação básica, com implicações relevantes para a reprodução da força de trabalho docente e suas condições materiais de existência.

Palavras-chave: Política Educacional. Financiamento da Educação Básica. Fundeb. PSPN. Remuneração.

\section{Contributions to a Fundeb Balance: redistribution of resources, remuneration expenses and teaching employment}

\begin{abstract}
This paper investigates effects of the Fund for Maintenance and Development of Basic Education and the Valorization of Education Professionals (Fundeb) on the conditions of the teaching work. For this, the dimensions were analyzed: municipalization of enrollments and fund resources; student / year value and the National Professional Salary Floor (PSPN); use of Fundeb resources to pay education professionals in state networks; types of employment contracts of teachers in state networks. We worked with the educational legislation, budgetary and financial data made available by the Union and by the Institute of Educational Studies and Research Anísio Teixeira. It was found that Fundeb, in the analyzed dimensions, promoted substantial changes in the Brazilian educational policy of basic education, with relevant implications for the reproduction of the teaching workforce and their material conditions of existence.
\end{abstract}

Keywords: Educational Policy. Basic Education Funding. Fundeb. PSPN. Remuneration. 
Contribuições para um Balanço do Fundeb

\section{Introdução}

A Emenda Constitucional n. 53/2006, que instituiu o Fundo de Manutenção e Desenvolvimento da Educação Básica e de Valorização dos Profissionais da Educação (Fundeb) (BRASIL, 2006), afirmou "[...] regras constitucionais, legado de políticas prévias e o ciclo da política [que estrutura] arenas decisórias, [...] fundamental para compreender o sucesso ou o fracasso de dada política pública" (ARAÚJO, 2011, p. 3). Tal emenda, entre outras medidas, também estabeleceu que o Fundeb vigoraria até o final de 2020.

Importa destacar, para os propósitos deste artigo, que do valor recebido do Fundeb por cada ente federativo está assegurada a aplicação mínima de $60 \%$ dos seus recursos para o pagamento da remuneração dos profissionais do magistério. Essa regra expressa a disputa por setores sociais em torno dos recursos da educação, pois, como lembrou o Departamento Intersindical de Estudos e Estatísticas Socieconômicos (DIEESE), no momento da primeira formulação do Fundeb, "[...] do total dos recursos vinculados ao fundo, $80 \%$ deveria ser destinado (sic) para o pagamento dos professores e funcionários da educação" (DIEESE, 2005, p. 4).

O Fundeb estendeu o financiamento a todas as etapas e modalidades da educação básica, o que implicou a ampliação de recursos. O mecanismo operacional do Fundeb replica, na prática, o do Fundo de Manutenção e Desenvolvimento do Ensino Fundamental e de Valorização do Magistério (Fundef) que vigorou de 1996 a 2006. Com um montante menor de receitas, esse fundo teve como foco o Ensino Fundamental, cuja redistribuição entre redes estaduais e municipais levava em conta o valor aluno ano e as matrículas do ensino regular dessa etapa da educação básica (BRASIL, 1996b). Nessas condições, a partir de 1998, quando foi efetivado nacionalmente, houve um intenso processo de disputa por alunos do ensino fundamental por parte dos municípios, como forma de obter mais recursos. Processo que ficou conhecido como "municipalização", uma vez que inúmeras redes municipais assumiram classes, escolas, docentes e matrículas das redes estaduais ou criaram suas próprias escolas. Assim, ao entrar em vigor, o Fundeb já encontrou redes de ensino fortemente municipalizadas.

A legislação do Fundeb também demandou a aprovação de Lei para implantar o Piso Salarial Profissional Nacional (PSPN) e encontrou forte presença de professores em solos municipais, ente federativo que apresenta grande variação de capacidade de arrecadação de impostos e de recebimento de transferências constitucionais e adicionais.

A aprovação do PSPN em lei se deu um ano após o previsto (BRASIL, 2008). Esse fato, contudo, não significou a imediata incorporação e ampliação de direitos docentes. Ao contrário, ao ser questionada por governadores por meio de Ação Direta de Inconstitucionalidade (ADIn), a lei do Piso transformou-se em contenda federativa que só veio a ser parcialmente resolvida em 2011, quando o Supremo Tribunal Federal (STF) julgou a ação e deu ganho de causa à União. Perante isso, estados e municípios deveriam pagar o PSPN e garantir demais direitos docentes (BRASIL, 2008; 2013). Em abril de 2020, em novo julgamento de aspectos do PSPN, o STF reconheceu que a jornada de trabalho docente deve ser composta por $2 / 3$ de trabalho em interação com alunos e $1 / 3$ em atividades de apoio à docência (BRASIL, 2020h). 
A conjuntura político-econômica a partir de 2015 foi marcada por medidas de restrição orçamentária em razão de recessão econômica. Em 2016, à crise econômica somou-se uma crise política, cujas medidas de enfrentamento adotadas pelo governo federal instauraram um contexto de profunda austeridade fiscal marcado pela aprovação da Emenda Constitucional n. 95 (BRASIL, 2016). Medidas como essa praticamente feriram de morte (AMARAL, 2016) o novo Plano Nacional de Educação 2014-2024 (BRASIL, 2014) que, entre outras medidas de ampliação do direito à educação, instituiu um patamar de gasto em educação de $10 \%$ do Produto Interno Bruto (PIB) até o final de sua vigência. Sobre o período imediatamente anterior, e que se estendeu até 2015, Amaral (2017), ao analisar a evolução de arrecadação de impostos pela União, entre 2003 a 2015, observa:

[...] que os anos de 2014 e 2015 já mostram uma inflexão no crescimento do PIB e na arrecadação de impostos pela União. Esse declínio da economia, que se explicitou claramente a partir de 2014, foi decisivo para a aglutinação de forças oposicionistas ao governo do Partido dos Trabalhadores (PT), o que resultou no impeachment de Dilma Rousseff no mês de agosto de 2016 e se caracterizou como um verdadeiro golpe legislativo-judicial-midiático (AMARAL, 2017, p. 5).

A disputa em torno da instituição de um novo Fundeb ${ }^{1}$ segue no Parlamento, não obstante o intenso envolvimento de setores da sociedade brasileira na defesa de qual deveria ser a parte do fundo público para financiar a educação. Mais uma vez emergem disputas em torno do financiamento da educação por uma escola pública, laica, democrática e socialmente referenciada, em contraposição a uma educação privada-mercantil com financiamento público. Eis os desafios postos pela atual conjuntura de austeridade fiscal, no contexto do ultraliberalismo ${ }^{2}$ na economia e da pauta conservadora nos costumes.

Sobre o novo Fundeb, importa ressaltar a posição defendida pela Associação Nacional de Pesquisa em Financiamento da Educação (FINEDUCA) por meio de Manifestação Pública, que contou com o apoio da Associação Nacional de Pós-Graduação e Pesquisa em Educação (ANPEd), Associação Nacional de Política e Administração da Educação (ANPAE), Campanha Nacional pelo Direito à Educação e Centro de Estudos Educação e Sociedade (CEDES):

(1) proteger o conjunto dos recursos da educação pública e superar obstáculos à promoção de maior justiça federativa no financiamento da educação básica e (2) fortalecer a educação básica pública, inscrevendo-a como única destinatária dos recursos do Fundeb, dada sua primazia como promotora de um projeto democrático de sociedade capaz de garantir o direito de todos à educação (FINEDUCA, 2020, p. 1-2).

1 Há três Propostas de Emenda à Constituição Federal (PECs) que tramitam no Congresso Nacional, a saber: PECs 15/2015, 33/2019 e 65/2019. (BRASIL, 2020f). Disponível em: <https://www12.senado.leg.br/noticias/materias/2020/01/06/manter-o-fundeb-e-garantir-recursos-saodesafios-do-congresso-em-2020>. Acesso em: 07 jan. 2020.

2 O conceito de ultraliberalismo empregado aqui se refere à tessitura social que promoveu e apoiou no contexto brasileiro, em 2016, "[...] o golpe (de Estado) do impeachment, que teve o consórcio entre o grande capital (internacional e nacional), parte do sistema partidário, o Poder Judiciário, as classes médias superiores e a grande mídia, [que] vem adotando políticas ultraliberais sem o escrutínio do voto e consequentemente da legitimidade, caracterizando-se como Estado Ultraliberal de Exceção (FONSECA, 2019, p. 127). Tal projeto, após as eleições de 2018, passou a ser, em grande medida, representado pela equipe econômica reunida em torno do $38^{\circ}$ Presidente da República (ROCHA, 2019, p. 27). 
Diante do exposto, volta-se para a análise de efeitos do Fundeb, no período de 2009 a 2019, sobre 4 (quatro) dimensões: das matrículas, da redistribuição de recursos no âmbito do fundo estadual, das despesas com remunerações dos professores e do tipo de vínculo dos professores, visando contribuir para um balanço dessa política.

De modo geral, os dados analisados abarcam o período de 2009 a 2019, com exceção dos referentes às matrículas na educação básica (2007-2019) e ao tipo de vínculo empregatício dos professores (2011-2019). Os dados financeiros foram extraídos do site do Tesouro Nacional, órgão do Ministério da Economia, e do Sistema de Informações sobre Orçamentos Públicos em Educação (SIOPE), acomodado no sítio do Fundo Nacional de Desenvolvimento da Educação (FNDE), cujos valores foram corrigidos pelo Índice de Preços ao Consumidor Amplo (IPCA) do IBGE. Os dados de matrículas e de docentes foram encontrados no Censo Escolar disponíveis no site do Instituto de Estudos e Pesquisas Educacionais “Anísio Teixeira” (INEP).

A exposição está organizada de modo a focalizar sequencialmente cada uma das quatro dimensões. Assim, na próxima seção examina-se a redistribuição das receitas do Fundeb e a municipalização das matrículas. Detém-se, em seguida, em breve análise do valor aluno ano e do valor do PSPN, com vistas a contextualizar a referência e critério de redistribuição de recursos e do valor do Piso. Na terceira seção, a análise focaliza os recursos do Fundeb contabilizados como pagamento da remuneração dos profissionais do magistério e, por fim, examinam-se os dados sobre os tipos de vínculos empregatício de docentes. Nestas duas últimas seções são examinados apenas os dados do magistério das redes estaduais, tendo em vista a ausência de dados compilados sobre as redes municiais.

\section{Receitas do Fundeb e o efeito da municipalização}

É importante lembrar que o conceito de municipalização pode ter muitos sentidos, que vão desde as políticas de descentralização da alimentação e de transporte escolar da rede estadual para as redes municipais, na década de 1980, até as transferências de matrículas, equipamentos e de pessoal administrativo e docente das redes estaduais para as redes municipais, que ficaram ainda mais intensas a partir de 1998 após a implantação do Fundef em todo o País (ARELARO, 1999; SILVA, 2001; MARTINS; OLIVEIRA; BUENO, 2004; BASSI; GIL 1999; CAMARGO; OLIVEIRA; MANSANO FILHO, 1999).

No período analisado, o processo de crescimento das matrículas em redes municipais já havia se consagrado, ainda que, além dos processos já descritos, por meio da expansão de seu atendimento, com construção de escolas, por exemplo, ou mesmo na forma de convênios com entidades privadas (em geral, sem fins lucrativos) para atendimento da Educação Infantil (EI), a Educação Especial (EE) e a Educação de Jovens e Adultos (EJA).

$\mathrm{Na}$ Tabela 1 é possível perceber a dinâmica das matrículas nas redes estaduais e municipais e privadas conveniadas. Aos dados das redes municipais estão somados os dados das instituições conveniadas (pois é principalmente entre elas que se estabelecem convênios de atendimento, em geral para a Educação Infantil), obtendo-se um Total "Municipal", bem como uma coluna com o Total Estadual e "Municipal" das matrículas. 
Contribuições para um Balanço do Fundeb

Tabela 1 - Brasil - Número de Matrículas por dependência administrativa em milhões (2009-2019)

\begin{tabular}{|c|c|c|c|c|c|}
\hline Ano & Estadual & Municipal & $\begin{array}{c}\text { Privada } \\
\text { conveniada } \\
\text { sem fins } \\
\text { lucrativos }\end{array}$ & $\begin{array}{c}\text { Total } \\
\text { "Municipal" }\end{array}$ & $\begin{array}{c}\text { Total Estadual } \\
\text { e "Municipal" }\end{array}$ \\
\hline $\mathbf{2 0 0 7}$ & 21,9 & 24,5 & $\mathrm{n}$ & $\mathrm{n}$ & 46,4 \\
\hline $\mathbf{2 0 0 8}$ & 21,4 & 24,5 & 1,0 & 25,5 & 46,9 \\
\hline $\mathbf{2 0 0 9}$ & 20,7 & 24,3 & 1,1 & 25,4 & 46,2 \\
\hline $\mathbf{2 0 1 0}$ & 20,0 & 23,7 & 1,2 & 24,9 & 44,9 \\
\hline $\mathbf{2 0 1 1}$ & 19,5 & 23,3 & 1,2 & 24,5 & 44,0 \\
\hline $\mathbf{2 0 1 2}$ & 18,7 & 23,2 & 1,2 & 24,4 & 43,2 \\
\hline $\mathbf{2 0 1 3}$ & 17,9 & 23,2 & 1,2 & 24,4 & 42,4 \\
\hline $\mathbf{2 0 1 4}$ & 17,3 & 23,1 & 1,2 & 24,3 & 41,6 \\
\hline $\mathbf{2 0 1 5}$ & 16,5 & 22,8 & 1,1 & 23,9 & 40,5 \\
\hline $\mathbf{2 0 1 6}$ & 16,6 & 22,8 & 1,1 & 24 & 40,6 \\
\hline $\mathbf{2 0 1 7}$ & 16,2 & 23,1 & 1,1 & 24,2 & 40,4 \\
\hline $\mathbf{2 0 1 8}$ & 15,9 & 23,1 & 1,0 & 24,1 & 40,1 \\
\hline $\mathbf{2 0 1 9}$ & 15,3 & 23,0 & 0,9 & 23,9 & 39,2 \\
\hline
\end{tabular}

Fonte: Elaboração dos autores, com base em dados do Laboratório de Dados Educacionais - UFPR obtidos nos Microdados do INEP, $\mathrm{n}$ significa sem dados para o ano.

É possível perceber que em todas as dependências administrativas há redução do número de matrículas no período observado. As redes estaduais passam de 21,7 milhões em 2007 para 15,3 milhões em 2019 (uma diferença de 6,4 milhões). As redes municipais saem de 24,5 milhões e atingem 23 milhões (queda de 1,5 milhão) e as redes conveniadas sem fins lucrativos partem de 1 milhão em 2008 (os dados do setor privado não se encontram desagregados em 2007) e crescem, atingindo um patamar de 1,2 milhão entre 2010 e 2014, quando começam a decrescer e chegam a cerca de 900 mil matrículas (cem mil matrículas a menos em relação a 2008). Isso faz com que a coluna do Total "Municipal" se inicie em 25,5 milhões em 2008 e termine com 23,9 milhões de matrículas (1,6 milhão de diferença). O Total Estadual e "Municipal" parte de 46,9 milhões em 2008 e chega a 39,2 milhões em 2019, uma diferença de 7,7 milhões de matrículas.

Portanto, pode-se ver de forma nítida que houve maior diminuição nas redes estaduais (-6,4 milhões) do que nas redes municipais ( $-1,5$ milhão), mesmo quando se somam as matrículas das redes conveniadas às municipais. Nesse sentido, não se pode afirmar que houve uma expansão das matrículas no atendimento municipal, como o conceito de municipalização poderia indicar. Tal processo ocorreu no período do Fundef. No entanto, na média nacional, houve uma diminuição do atendimento em menor magnitude nas redes municipais do que nas redes estaduais (embora em alguns estados o atendimento possa ter subido, em outros, certamente, caiu), implicando a dinâmica de redistribuição dos recursos da política de fundos em favor dos municípios, constituindo assim um processo de municipalização dos recursos, como se verá adiante. 
Ao se tomar como parâmetro os percentuais de atendimento de matrículas Estadual diante do Total Estadual e "Municipal", confirma-se o movimento, pois, em 2008, as redes estaduais correspondiam a 45,6\%, enquanto o Total "Municipal" era equivalente a 54,4\%; contudo, em 2019, o percentual das redes estaduais foi de $39,0 \%$ enquanto o Total "Municipal" foi de $61,0 \%$.

Para o tratamento dos recursos redistribuídos pela totalidade dos fundos com a complementação da União, a Tabela 2 apresenta os montantes em Reais. Os recursos recebidos pelo conjunto dos estados e dos municípios entre 2009 e 2019. Pode-se observar que o valor total da somatória de todos os fundos do País, em 2009, com a complementação da União, correspondeu a R\$ 128,6 bilhões, e, em 2019, a R\$168,5 bilhões. Entre 2009 e 2014 houve crescimento dos valores totais, alcançando o maior valor em 2014 , $R \$ 166,1$ bilhões, decaindo depois para cerca de $\mathrm{R} \$ 157,2$ bilhões em 2016, com aumentos posteriores.

Tabela 2 - Receita total do Fundeb redistribuída aos estados, aos municípios e ao Distrito Federal, 2009-2019 (valores em milhões, corrigidos em R\$ de dez. 2019 - IPCA/IBGE)

\begin{tabular}{|c|c|c|c|}
\hline Ano & Estados & Municípios & Total \\
\hline 2009 & 62.081 & 66.548 & 128.628 \\
\hline 2010 & 65.826 & 73.186 & 139.012 \\
\hline 2011 & 71.287 & 83.009 & 154.296 \\
\hline 2012 & 71.889 & 85.672 & 157.561 \\
\hline 2013 & 73.536 & 89.750 & 163.286 \\
\hline 2014 & 73.947 & 92.154 & 166.101 \\
\hline 2015 & 68.962 & 90.339 & 159.300 \\
\hline 2016 & 66.718 & 90.486 & 157.203 \\
\hline 2017 & 67.151 & 90.310 & 157.462 \\
\hline 2018 & 66.009 & 93.649 & 159.657 \\
\hline 2019 & 68.539 & 99.999 & 168.538 \\
\hline $\begin{array}{c}\text { Variação } \\
\text { percentual }\end{array}$ & $10 \%$ & $50 \%$ & $31 \%$ \\
\hline
\end{tabular}

Fonte: Elaboração dos autores com base em dados de Brasil (2020a).

O crescimento percentual dos valores totais recebidos do período foi de $31 \%$ em termos reais. A variação percentual dos montantes da somatória dos estados foi de $10 \%$, enquanto a dos municípios foi de $50 \%$ de aumento real no período.

Destaque-se que os valores da somatória dos montantes dos estados foram sempre menores do que os montantes destinados aos municípios. Para os estados, os montantes saem de $R \$ 62,1$ bilhões em 2009, sobem até $R \$ 73,5$ e $R \$ 74,0$ bilhões em 2013 e 2014 e, em seguida, decrescem atingindo o menor valor em 2018, com $\mathrm{R} \$ 66,0$ bilhões, voltando a crescer para $\mathrm{R} \$ 68,5$ bilhões em 2019. Para os municípios, eles saem de $\mathrm{R} \$ 66,5$ bilhões em 2009 , crescem até alcançar $R \$ 92,2$ bilhões em 2014 , decrescendo para cerca de $R \$ 90,3$ bilhões em 2017. Em seguida, voltam a crescer, chegando a R \$ 93,7 bilhões em 2018 e R\$ 100 bilhões em 2019. Ou seja, há maior destinação dos recursos redistribuídos do Fundeb aos municípios (mesmo não ocasionado pelo aumento de matrículas), ocorrendo o que poderia também ser reconhecido como municipalização dos recursos do Fundeb. 
Contribuições para um Balanço do Fundeb

Quando se trabalha com valores percentuais, a municipalização da redistribuição dos recursos do Fundeb fica mais nítida, pois os percentuais dos montantes totais destinados pelos fundos aos estados passam de $48 \%$ em 2009 e alcançam $41 \%$ em 2019, enquanto os percentuais destinados aos municípios, no mesmo período, passam de $52 \%$ para $59 \%$. Entretanto, é bom lembrar que essa situação pode variar em cada fundo estadual e no Distrito Federal, a cada ano, de acordo com a arrecadação de impostos, a ampliação do atendimento municipal (municipalização de matrículas), ou mesmo com uma diminuição do atendimento municipal em termos absolutos, mas que em termos percentuais ele seja maior do que o atendimento estadual.

$\mathrm{Na}$ Tabela 3 é possível perceber que há grandes disparidades entre os fundos em cada estado e no Distrito Federal. Em 2009, o menor valor dos montantes se encontrava em Roraima, com R $\$ 424$ milhões, e, o maior, era o de São Paulo, com R 18.818 milhões. Em 2019, o menor valor continua em Roraima, com $\mathrm{R} \$ 453$ milhões, e, o maior valor, em São Paulo, com R\$ 17.342 milhões. Observa-se ainda que, no geral, houve uma tendência de crescimento no período, com exceção do Rio de Janeiro, onde houve um decréscimo dos valores, pois passou de $\mathrm{R} \$ 3.370$ milhões para $\mathrm{R} \$ 2.728$ milhões $(-19 \%)$ e de São Paulo, que encolheu de $\mathrm{R} \$ 18.818$ milhões para $\mathrm{R} \$ 17.342$ milhões (-8\%). Mas há 6 estados com mais de $20 \%$ de crescimento, sendo $65 \%$ no Amazonas, $48 \%$ no Pará, $33 \%$ no Mato Grosso, $28 \%$ no Acre e no Piauí, e $23 \%$ no Ceará. Os demais tiveram crescimento de até $20 \%$.

Tabela 3 - Receita redistribuída aos estados e ao Distrito Federal, 2009-2019 (valores em milhões, corrigidos em R\$ de dez 2019 - IPCA/IBGE)

\begin{tabular}{|c|c|c|c|c|c|c|c|c|c|c|c|c|}
\hline Estados & 2009 & 2010 & 2011 & 2012 & 2013 & 2014 & 2015 & 2016 & 2017 & 2018 & 2019 & $\begin{array}{c}\text { Variação } \\
\text { 2009-2019 }\end{array}$ \\
\hline $\mathrm{AC}$ & 531 & 541 & 602 & 616 & 634 & 632 & 602 & 637 & 614 & 673 & 680 & $28 \%$ \\
\hline $\mathrm{AL}$ & 634 & 672 & 792 & 822 & 782 & 787 & 770 & 731 & 662 & 705 & 725 & $14 \%$ \\
\hline $\mathrm{AM}$ & 1.125 & 1.360 & 1.388 & 1.619 & 1.732 & 1.710 & 1.603 & 1.532 & 1.952 & 1.826 & 1.855 & $65 \%$ \\
\hline $\mathrm{AP}$ & 559 & 573 & 635 & 662 & 674 & 653 & 584 & 597 & 547 & 567 & 583 & $4 \%$ \\
\hline BA & 2.944 & 3.095 & 3.474 & 3.812 & 3.652 & 3.583 & 3.391 & 3.308 & 3.245 & 3.299 & 3.321 & $13 \%$ \\
\hline $\mathrm{CE}$ & 1.363 & 1.400 & 1.712 & 1.666 & 1.673 & 1.739 & 1.653 & 1.665 & 1.555 & 1.550 & 1.680 & $23 \%$ \\
\hline DF & 2.056 & 1.983 & 2.034 & 2.210 & 2.216 & 2.267 & 2.162 & 2.138 & 2.164 & 2.586 & 2.128 & $4 \%$ \\
\hline ES & 1.031 & 1.094 & 1.120 & 1.174 & 1.205 & 1.163 & 1.097 & 987 & 965 & 1.004 & 1.033 & $0 \%$ \\
\hline $\mathrm{GO}$ & 1.861 & 1.987 & 2.156 & 2.314 & 2.280 & 2.264 & 2.133 & 2.129 & 2.110 & 2.041 & 2.146 & $15 \%$ \\
\hline MA & 1.330 & 1.271 & 1.749 & 1.723 & 1.488 & 1.467 & 1.503 & 1.526 & 1.409 & 1.444 & 1.501 & $13 \%$ \\
\hline MG & 6.868 & 7.457 & 7.749 & 7.923 & 8.240 & 8.229 & 7.418 & 7.561 & 7.608 & 5.468 & 8.000 & $16 \%$ \\
\hline MS & 962 & 984 & 1.084 & 1.083 & 1.117 & 1.108 & 1.022 & 1.022 & 1.045 & 1.084 & 1.126 & $17 \%$ \\
\hline MT & 1.294 & 1.277 & 1.396 & 1.457 & 1.559 & 1.629 & 1.536 & 1.659 & 1.613 & 1.648 & 1.726 & $33 \%$ \\
\hline PA & 1.641 & 1.803 & 2.291 & 2.378 & 2.169 & 2.306 & 2.368 & 2.277 & 2.359 & 2.281 & 2.422 & $48 \%$ \\
\hline PB & 1.004 & 1.014 & 1.206 & 1.172 & 1.176 & 1.169 & 1.111 & 1.099 & 1.070 & 1.050 & 1.076 & $7 \%$ \\
\hline PE & 2.276 & 2.344 & 2.753 & 2.663 & 2.574 & 2.630 & 2.358 & 2.300 & 2.230 & 2.181 & 2.271 & $0 \%$ \\
\hline PI & 788 & 794 & 936 & 920 & 902 & 847 & 776 & 828 & 931 & 1.010 & 1.012 & $28 \%$ \\
\hline PR & 3.810 & 3.968 & 4.314 & 4.456 & 4.695 & 4.746 & 4.651 & 4.526 & 4.624 & 4.615 & 4.519 & $19 \%$ \\
\hline $\mathrm{RJ}$ & 3.370 & 3.674 & 3.784 & 3.673 & 3.664 & 3.441 & 3.127 & 2.825 & 2.825 & 2.855 & 2.728 & $-19 \%$ \\
\hline $\mathrm{RN}$ & 866 & 891 & 997 & 1.020 & 927 & 870 & 1.027 & 944 & 921 & 930 & 898 & $4 \%$ \\
\hline RO & 731 & 785 & 857 & 837 & 843 & 874 & 826 & 829 & 775 & 802 & 851 & $16 \%$ \\
\hline RR & 424 & 411 & 452 & 428 & 448 & 447 & 413 & 438 & 388 & 389 & 453 & $7 \%$ \\
\hline $\mathrm{RS}$ & 4.275 & 4.552 & 4.646 & 4.597 & 4.835 & 4.903 & 4.622 & 4.646 & 4.533 & 4.683 & 4.411 & $3 \%$ \\
\hline $\mathrm{SC}$ & 2.239 & 2.443 & 2.633 & 2.538 & 2.457 & 2.537 & 2.347 & 2.327 & 2.377 & 2.428 & 2.565 & $15 \%$ \\
\hline SE & 635 & 670 & 721 & 737 & 737 & 729 & 675 & 682 & 660 & 697 & 683 & $8 \%$ \\
\hline SP & 18.818 & 20.347 & 21.001 & 21.062 & 21.655 & 20.680 & 18.891 & 17.424 & 17.393 & 17.298 & 17.342 & $-8 \%$ \\
\hline TO & 769 & 773 & 899 & 893 & 906 & 903 & 834 & 851 & 785 & 792 & 805 & $5 \%$ \\
\hline Totais & 62.290 & 66.329 & 71.518 & 72.410 & 73.935 & 74.194 & 69.499 & 67.490 & 67.361 & 65.904 & 68.539 & $10 \%$ \\
\hline
\end{tabular}


Contribuições para um Balanço do Fundeb

Quando se observa a Tabela 4, que apresenta os totais redistribuídos aos municípios por fundo em cada estado no País, também se percebe grandes diferenças, pois se identifica que em 2009 os menores montantes estavam em Roraima, com R 198 milhões (o menor), e no Amapá, com R\$ 210 milhões, enquanto, no mesmo ano, os maiores montantes eram os da Bahia, com R $\$ 5.589$ milhões, e os de São Paulo, com R\$ 14.882 milhões (o maior). Em 2019 , os menores montantes continuaram no Amapá, com $\mathrm{R} \$ 347$ milhões (que passou a ser o menor), e em Roraima, com R\$383 milhões. No mesmo ano, os maiores também estão na Bahia, com R\$ 8.365 milhões, e em São Paulo, com R\$ 20.078 milhões.

No geral, no período de 2009 a 2019, os dados relativos à redistribuição dos recursos aos municípios tiveram uma tendência de maior crescimento do que o dos estados, pois todos tiveram uma variação percentual maior do que 30\%. Daqueles que cresceram menos percentualmente, identifica-se o Espírito Santo com 30\% e São Paulo com 35\%. Entre os que mais cresceram foram identificados: Roraima com 93\%, Tocantins com 85\%, o Amazonas com $82 \%$ e Santa Catarina com $80 \%$. Em 13 outros fundos do País o crescimento percentual esteve acima de $50 \%$.

Tabela 4 - Receita redistribuída aos municípios, 2009-2019 (valores em milhões, corrigidos em $\mathrm{R} \$$ de dez. 2019 - IPCA/IBGE)

\begin{tabular}{|c|c|c|c|c|c|c|c|c|c|c|c|c|}
\hline Estados & 2009 & 2010 & 2011 & 2012 & 2013 & 2014 & 2015 & 2016 & 2017 & 2018 & 2019 & $\begin{array}{c}\text { Variação } \\
\text { 2009-2019 }\end{array}$ \\
\hline $\mathrm{AC}$ & 280 & 305 & 339 & 352 & 350 & 382 & 372 & 389 & 379 & 393 & 412 & $47 \%$ \\
\hline $\mathrm{AL}$ & 1.455 & 1.520 & 1.869 & 1.854 & 1.884 & 1.994 & 1.994 & 2.005 & 1.792 & 2.021 & 2.102 & $44 \%$ \\
\hline $\mathrm{AM}$ & 1.288 & 1.568 & 1.614 & 1.909 & 2.030 & 2.037 & 1.943 & 1.904 & 2.353 & 2.255 & 2.343 & $82 \%$ \\
\hline AP & 210 & 225 & 258 & 265 & 285 & 328 & 322 & 329 & 325 & 330 & 347 & $65 \%$ \\
\hline BA & 5.589 & 6.229 & 7.390 & 8.034 & 7.816 & 8.001 & 8.109 & 8.169 & 7.748 & 8.167 & 8.365 & $50 \%$ \\
\hline $\mathrm{CE}$ & 3.630 & 3.933 & 4.861 & 4.667 & 4.735 & 4.886 & 4.922 & 5.146 & 4.569 & 4.890 & 5.382 & $48 \%$ \\
\hline ES & 1.639 & 1.772 & 1.959 & 2.051 & 2.126 & 2.069 & 1.995 & 1.856 & 1.851 & 1.963 & 2.127 & $30 \%$ \\
\hline GO & 1.759 & 1.982 & 2.222 & 2.557 & 2.696 & 2.741 & 2.631 & 2.669 & 2.647 & 2.732 & 2.769 & $57 \%$ \\
\hline MA & 3.466 & 3.486 & 4.801 & 4.884 & 4.749 & 5.243 & 5.596 & 5.717 & 5.044 & 5.436 & 5.805 & $67 \%$ \\
\hline MG & 5.120 & 5.776 & 6.147 & 6.321 & 6.784 & 6.829 & 6.364 & 6.655 & 6.512 & 4.789 & 7.335 & $43 \%$ \\
\hline MS & 1.037 & 1.092 & 1.224 & 1.257 & 1.364 & 1.417 & 1.362 & 1.402 & 1.382 & 1.470 & 1.550 & $49 \%$ \\
\hline MT & 1.035 & 1.061 & 1.114 & 1.137 & 1.203 & 1.289 & 1.281 & 1.369 & 1.387 & 1.529 & 1.628 & $57 \%$ \\
\hline PA & 3.369 & 3.797 & 4.854 & 5.188 & 4.867 & 5.267 & 5.523 & 5.348 & 5.478 & 5.573 & 6.001 & $78 \%$ \\
\hline PB & 1.294 & 1.414 & 1.651 & 1.608 & 1.709 & 1.822 & 1.833 & 1.939 & 1.735 & 1.850 & 1.993 & $54 \%$ \\
\hline PE & 2.989 & 3.172 & 3.740 & 3.664 & 3.789 & 4.137 & 3.963 & 4.158 & 4.045 & 4.187 & 4.414 & $48 \%$ \\
\hline PI & 1.372 & 1.474 & 1.770 & 1.789 & 1.803 & 1.959 & 1.985 & 2.013 & 1.895 & 2.065 & 2.130 & $55 \%$ \\
\hline PR & 2.890 & 3.051 & 3.341 & 3.502 & 3.860 & 4.100 & 4.166 & 4.171 & 4.455 & 4.529 & 4.561 & $58 \%$ \\
\hline RJ & 4.895 & 5.602 & 5.949 & 6.336 & 7.156 & 7.081 & 6.673 & 6.315 & 6.272 & 7.015 & 6.698 & $37 \%$ \\
\hline $\mathrm{RN}$ & 1.114 & 1.203 & 1.373 & 1.407 & 1.321 & 1.261 & 1.583 & 1.520 & 1.481 & 1.562 & 1.619 & $45 \%$ \\
\hline RO & 548 & 607 & 677 & 666 & 674 & 691 & 674 & 676 & 683 & 732 & 777 & $42 \%$ \\
\hline $\mathrm{RR}$ & 198 & 197 & 221 & 225 & 258 & 295 & 302 & 324 & 310 & 320 & 383 & $93 \%$ \\
\hline RS & 3.351 & 3.802 & 4.070 & 4.229 & 4.555 & 4.638 & 4.540 & 4.704 & 4.838 & 5.202 & 5.294 & $58 \%$ \\
\hline $\mathrm{SC}$ & 2.088 & 2.360 & 2.622 & 2.766 & 3.050 & 3.190 & 2.964 & 3.129 & 3.322 & 3.553 & 3.753 & $80 \%$ \\
\hline SE & 813 & 907 & 1.010 & 1.030 & 1.067 & 1.118 & 1.081 & 1.093 & 1.062 & 1.175 & 1.166 & $43 \%$ \\
\hline SP & 14.822 & 16.653 & 17.534 & 17.929 & 19.407 & 18.958 & 18.097 & 17.664 & 18.185 & 18.835 & 20.078 & $35 \%$ \\
\hline TO & 521 & 556 & 665 & 666 & 700 & 725 & 766 & 872 & 845 & 929 & 967 & $85 \%$ \\
\hline Totais & 66.772 & 73.745 & 83.278 & 86.293 & 90.237 & 92.461 & 91.043 & 91.533 & 90.593 & 93.501 & 99.999 & $50 \%$ \\
\hline
\end{tabular}

Fonte: Elaboração dos autores com base em dados de Brasil (2020a).

Quando se compara a coluna do ano de 2019 dos recursos redistribuídos para os Estados (Tabela 3) com a coluna do mesmo ano para os recursos redistribuídos para os Municípios (Tabela 4), é possível perceber que, em apenas 6 estados (AC, AP, MG, MT, RO e RR), a diferença é positiva para os estados, enquanto nos demais a diferença é negativa, indicando clara destinação em favor dos municípios (o Distrito Federal não foi considerado). 
Contribuições para um Balanço do Fundeb

Além disso, o total dos montantes redistribuídos para os municípios foi de $\mathrm{R} \$ 100$ bilhões em 2019 , enquanto o total dos montantes redistribuídos para os Estados foi de $R \$ 68,5$ bilhões, ou seja, há uma diferença dos totais redistribuídos de $\mathrm{R} \$ 31,5$ bilhões para os Municípios. Esses dados permitem concluir que houve uma expansão significativa dos recursos redistribuídos pelos fundos para as redes municipais no País no período de 2009 a 2019, por conta do aumento percentual da presença municipal, ainda que estas apresentassem uma diminuição de atendimento às matrículas no período.

\section{Valor aluno/ano e PSPN realizados em contexto federativo}

O vínculo entre o Fundeb e o PSPN encontra-se firmemente estabelecido na lei que institui este último na forma de cálculo de atualização do valor do Piso com "[...] o mesmo percentual de crescimento do valor anual mínimo por aluno referente aos anos iniciais do ensino fundamental urbano, definido nacionalmente, nos termos da Lei n. 11.494, de 20 de junho de 2007" (BRASIL, 2008).

Assim, enquanto a Lei n. 11.494/07 determina ao Poder Executivo a publicação da estimativa do valor anual mínimo por aluno nacional para o ano seguinte até o dia 31 de dezembro de cada exercício, a Lei n. 11.738/08 define a atualização anual do valor do PSPN no mês de janeiro, com base no mesmo percentual da estimativa do valor mínimo nacional, mas com uma defasagem de um ano entre um e outro (BRASIL, 2007a; 2008).

O Gráfico 1 ilustra o vínculo entre o Valor Aluno Ano mínimo nacional (VAA), tomando especificamente o valor aluno de referência do ensino fundamental anos iniciais urbano, e o valor do PSPN, bem como mostra as variações percentuais de cada um. Convém advertir que os valores utilizados não correspondem aos valores nominais originalmente publicados a cada ano, uma vez que foram atualizados.

\section{Gráfico 1 - Brasil - Valor Aluno Ano Mínimo Nacional e PSPN, 2009-2019 (valores corrigidos em R\$ de dez. 2019 - IPCA/IBGE)}

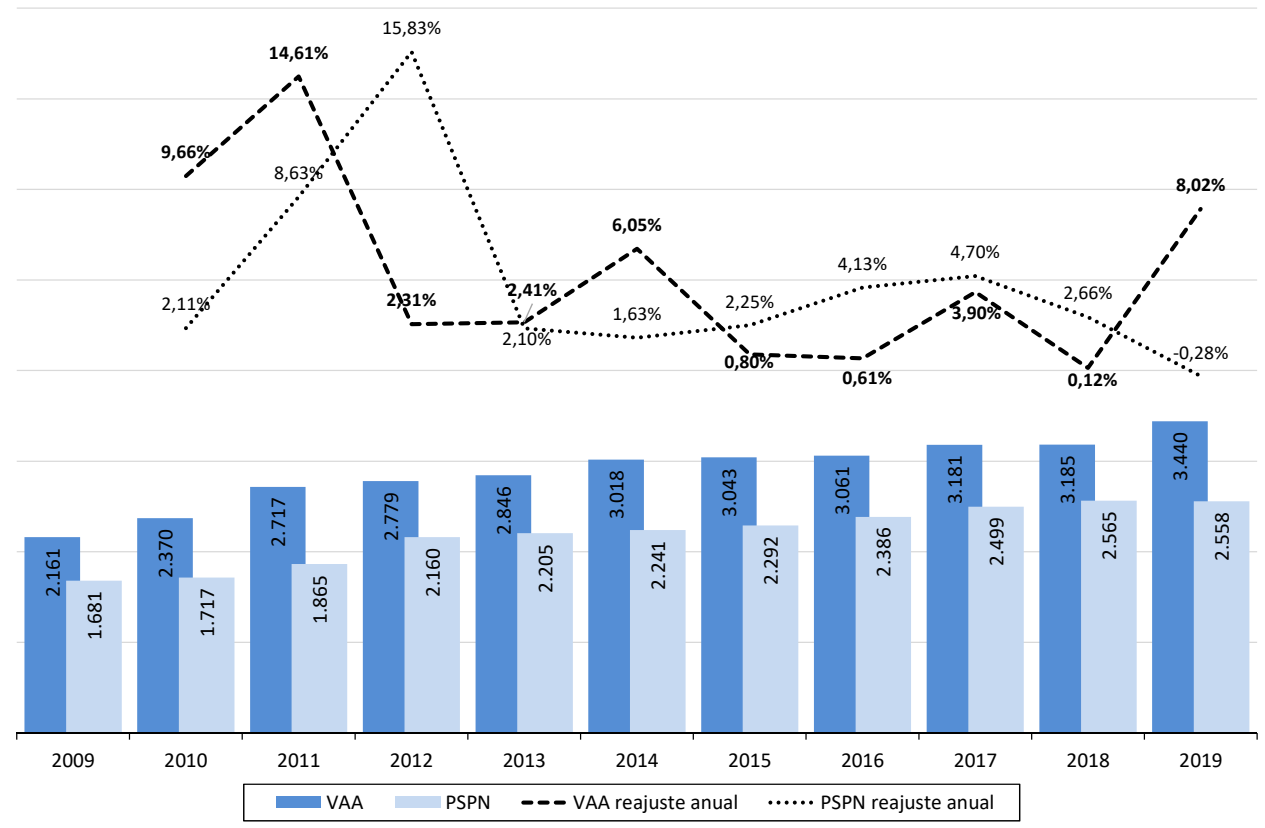

Fonte: Elaboração dos autores com base em dados de Brasil (2020b; 2020c). 
Contribuições para um Balanço do Fundeb

Desse modo, pode-se constatar que, despidos dos efeitos da inflação, os valores anuais do VAA e os do PSPN, de modo geral, apresentaram crescimento e ganho real constantes em todo o período, exceto para o valor do PSPN em 2019, ligeiramente inferior ao do ano anterior, o que quer dizer que nesse ano, especificamente, o reajuste aplicado não repôs toda a inflação do ano anterior. Isso pode ser conferido pelo valor do VAA de 2018, pouco superior ao de 2017. Ou seja, a ínfima correção que houve no VAA entre esses dois anos, a qual seria aplicada um ano depois no PSPN, acabou sendo inferior ao da inflação ocorrida ao longo do ano de 2019.

Esse contínuo crescimento do VAA e, por conseguinte, do PSPN se explica pelo desempenho das variáveis que compõem o primeiro indicador: as receitas dos impostos que constituem a cesta do Fundeb e as matrículas da educação básica. Até 2014, o contexto foi favorável ao aumento da arrecadação dos impostos, a qual sofre inflexão pela recessão a partir de 2015, ao mesmo tempo que o Censo Escolar capturou a redução paulatina e significativa no número total das matrículas, como evidenciado acima. Mas por que então o VAA a partir de 2015 manteve-se crescente se também as receitas caíram? Certamente porque a queda no número de matrículas foi relativamente superior à queda na arrecadação, o que resultou em valores contidos do VAA, mas ainda ligeiramente crescentes até 2018. É interessante atentar para o argumento de Sonobe, Pinto e Ribeiro (2018) que compreenderam o movimento de redução das matrículas como uma estratégia das redes estaduais para elevar o VAA exatamente em momento que se esperava a ampliação do atendimento determinado pela ampliação da obrigatoriedade.

Ao observar-se o desempenho dos percentuais de reajuste de cada indicador, verificase o crescimento real efetivo, exceto, como assinalado, para o valor do PSPN em 2019, que ficou $0,28 \%$ inferior à taxa de inflação desse ano. Notáveis, positivamente, são as taxas de reajuste do VAA (14,61\%) em 2011 e do PSPN em 2012 (15,83\%). Desse modo, o PSPN e o Fundeb asseguraram ganhos reais que, caso tenham sido repassados aos vencimentos dos professores, materializaram a valorização do magistério nesse aspecto da remuneração, mesmo com menores percentuais de ganho real entre 2015 e 2018 expressos no VAA.

\section{Receitas do Fundeb e o pagamento dos profissionais da educação básica das redes estaduais de ensino}

Ao considerar o vínculo importante entre as receitas do Fundeb e a implementação de uma política de remuneração capaz de valorizar os profissionais da educação é fundamental a análise da dinâmica operacionalizada por meio das transferências de recursos intergovernamentais entre estados e seus respectivos municípios, o que pode ser observado na Tabela 5, que apresenta os resultados líquidos das transferências dos recursos do Fundeb dos governos estaduais, que em todos os estados foram negativos. Isso significa que parte importante das receitas estaduais subvinculadas ao Fundo é transferida aos governos municipais. 
Contribuições para um Balanço do Fundeb

Tabela 5 - Governos estaduais - Receitas destinadas, receitas recebidas e diferença percentual do resultado líquido, 2009/2012/2014/2016/2019 (valores em milhões, corrigidos em R\$ de dez. 2019 - IPCA/IBGE)

\begin{tabular}{|c|c|c|c|c|c|c|c|c|c|c|c|c|c|c|c|}
\hline \multirow{2}{*}{ Estados } & \multicolumn{3}{|c|}{2009} & \multicolumn{3}{|c|}{2012} & \multicolumn{3}{|c|}{2014} & \multicolumn{3}{|c|}{2016} & \multicolumn{3}{|c|}{2019} \\
\hline & Dest. & Rec. & Dif. $\%$ & Dest. & Rec. & Dif.\% & Dest. & Rec. & Dif.\% & Dest. & Rec. & Dif. \% & Dest. & Rec. & Dif.\% \\
\hline $\mathbf{A C}$ & 678 & 531 & $-22 \%$ & 811 & 616 & $-24 \%$ & 842 & 632 & $-25 \%$ & 858 & 637 & $-26 \%$ & 900 & 681 & $-24 \%$ \\
\hline $\mathbf{A L}$ & 1.143 & 522 & $-54 \%$ & 1.345 & 619 & $-54 \%$ & 1.408 & 799 & $-43 \%$ & 1.553 & 758 & $-51 \%$ & 1.498 & 564 & $-62 \%$ \\
\hline $\mathbf{A M}$ & 1.655 & 1.074 & $-35 \%$ & 2.047 & 1.313 & $-36 \%$ & 2.134 & 1.380 & $-35 \%$ & 1.812 & 1.140 & $-37 \%$ & 2.129 & 1.335 & $-37 \%$ \\
\hline $\mathbf{A P}$ & 667 & 559 & $-16 \%$ & 795 & 662 & $-17 \%$ & 836 & 653 & $-22 \%$ & 798 & 597 & $-25 \%$ & 817 & 584 & $-28 \%$ \\
\hline BA & 4.102 & 2.266 & $-45 \%$ & 4.873 & 2.498 & $-49 \%$ & 5.385 & 2.715 & $-50 \%$ & 5.178 & 2.342 & $-55 \%$ & 5.594 & 2.517 & $-55 \%$ \\
\hline $\mathbf{C E}$ & 2.580 & 1.066 & $-59 \%$ & 3.081 & 1.230 & $-60 \%$ & 3.320 & 1.313 & $-60 \%$ & 3.320 & 1.217 & $-63 \%$ & 3.641 & 1.254 & $-66 \%$ \\
\hline ES & 1.742 & 1.031 & $-41 \%$ & 2.101 & 1.174 & $-44 \%$ & 2.210 & 1.163 & $-47 \%$ & 1.910 & 987 & $-48 \%$ & 2.133 & 1.035 & $-51 \%$ \\
\hline GO & 2.298 & 1.861 & $-19 \%$ & 3.145 & 2.314 & $-26 \%$ & 3.285 & 2.264 & $-31 \%$ & 3.085 & 2.129 & $-31 \%$ & 3.182 & 2.146 & $-33 \%$ \\
\hline MA & 1.841 & 767 & $-58 \%$ & 2.205 & 860 & $-61 \%$ & 2.392 & 758 & $-68 \%$ & 2.481 & 764 & $-69 \%$ & 2.549 & 1.503 & $-41 \%$ \\
\hline MG & 7.267 & 6.806 & $-6 \%$ & 8.778 & 7.927 & $-10 \%$ & 9.263 & 8.335 & $-10 \%$ & 8.648 & 7.644 & $-12 \%$ & 9.456 & 8.062 & $-15 \%$ \\
\hline MS & 1.341 & 962 & $-28 \%$ & 1.562 & 1.083 & $-31 \%$ & 1.696 & 1.108 & $-35 \%$ & 1.605 & 1.022 & $-36 \%$ & 1.743 & 1.126 & $-35 \%$ \\
\hline MT & 1.567 & 1.294 & $-17 \%$ & 1.465 & 1.457 & $-1 \%$ & 1.947 & 1.629 & $-16 \%$ & 1.994 & 1.659 & $-17 \%$ & 2.264 & 1.726 & $-24 \%$ \\
\hline PA & 2.276 & 1.085 & $-52 \%$ & 2.842 & 1.297 & $-54 \%$ & 3.121 & 1.333 & $-57 \%$ & 3.002 & 1.277 & $-57 \%$ & 3.152 & 1.312 & $-58 \%$ \\
\hline PB & 1.357 & 916 & $-33 \%$ & 1.674 & 1.074 & $-36 \%$ & 1.816 & 1.088 & $-40 \%$ & 1.777 & 977 & $-45 \%$ & 1.859 & 985 & $-47 \%$ \\
\hline PE & 2.991 & 1.934 & $-35 \%$ & 3.720 & 2.328 & $-37 \%$ & 3.919 & 2.253 & $-43 \%$ & 3.746 & 1.985 & $-47 \%$ & 4.040 & 2.283 & $-43 \%$ \\
\hline PI & 1.099 & 620 & $-44 \%$ & 1.340 & 721 & $-46 \%$ & 1.452 & 679 & $-53 \%$ & 1.455 & 648 & $-55 \%$ & 1.529 & 1.014 & $-34 \%$ \\
\hline PR & 4.152 & 3.810 & $-8 \%$ & 4.988 & 4.456 & $-11 \%$ & 5.615 & 4.746 & $-15 \%$ & 5.518 & 4.526 & $-18 \%$ & 5.728 & 4.519 & $-21 \%$ \\
\hline RJ & 5.816 & 3.370 & $-42 \%$ & 7.069 & 3.673 & $-48 \%$ & 7.324 & 3.441 & $-53 \%$ & 6.451 & 2.825 & $-56 \%$ & 6.531 & 2.751 & $-58 \%$ \\
\hline RN & 1.317 & 835 & $-37 \%$ & 1.609 & 1.002 & $-38 \%$ & 1.639 & 1.026 & $-37 \%$ & 1.666 & 944 & $-43 \%$ & 1.692 & 898 & $-47 \%$ \\
\hline RO & 952 & 731 & $-23 \%$ & 1.135 & 837 & $-26 \%$ & 1.175 & 874 & $-26 \%$ & 1.135 & 829 & $-27 \%$ & 1.211 & 853 & $-30 \%$ \\
\hline $\mathbf{R R}$ & 493 & 427 & $-13 \%$ & 565 & 428 & $-24 \%$ & 602 & 447 & $-26 \%$ & 616 & 438 & $-29 \%$ & 667 & 454 & $-32 \%$ \\
\hline $\mathbf{R S}$ & 4.811 & 4.275 & $-11 \%$ & 5.683 & 4.597 & $-19 \%$ & 6.087 & 4.909 & $-19 \%$ & 5.966 & 4.646 & $-22 \%$ & 6.275 & 4.411 & $-30 \%$ \\
\hline SC & 2.680 & 2.222 & $-17 \%$ & 3.359 & 2.538 & $-24 \%$ & 3.667 & 2.537 & $-31 \%$ & 3.492 & 2.327 & $-33 \%$ & 4.116 & 2.565 & $-38 \%$ \\
\hline SE & 1.062 & 635 & $-40 \%$ & 1.293 & 737 & $-43 \%$ & 1.344 & 729 & $-46 \%$ & 1.313 & 682 & $-48 \%$ & 1.353 & 683 & $-49 \%$ \\
\hline SP & 23.033 & 18.746 & $-19 \%$ & 26.698 & 21.028 & $-21 \%$ & 26.302 & 20.443 & $-22 \%$ & 23.280 & 17.424 & $-25 \%$ & 25.115 & 17.337 & $-31 \%$ \\
\hline TO & 926 & 744 & $-20 \%$ & 1.155 & 893 & $-23 \%$ & 1.197 & 903 & $-25 \%$ & 1.277 & 851 & $-33 \%$ & 1.317 & 805 & $-39 \%$ \\
\hline Totais & 79.845 & 59.089 & $-26 \%$ & 95.335 & 67.360 & $-29 \%$ & 99.979 & 68.158 & $-32 \%$ & 93.846 & 61.262 & $-35 \%$ & 95.246 & 60.008 & $-37 \%$ \\
\hline
\end{tabular}

Fonte: Elaboração dos autores com base em dados de Brasil (2020a).

Os dados da Tabela 5 evidenciam os percentuais de repasses/perdas de receitas decorrentes da relação entre valor-aluno/ano, recursos e matrículas ponderadas. Desse modo, é possível observar que os percentuais de transferências de receitas dos governos estaduais, em 2009, foram acima de 30\% em 13 estados e, em 2019, em 19 estados.

Os estados que recebem complementação de receita da União são aqueles com maiores percentuais de perdas, que são reduzidas parcialmente com as transferências da União.

Essa situação, a depender da capacidade de financiamento do estado, poderá impactar negativamente no desenvolvimento de uma política de valorização dos professores por meio da remuneração. 
Contribuições para um Balanço do Fundeb

Tabela 6 - Despesas do Fundeb com Remunerações e Encargos dos Profissionais do Magistério, 2009/2012/2014/2016/2019 (valores em milhões, corrigidos em R\$ de dez. 2019 IPCA/IBGE)

\begin{tabular}{|c|c|c|c|c|c|c|}
\hline Estados & 2009 & 2012 & 2014 & 2016 & 2019 & $\begin{array}{c}\text { Variação } \\
\text { 2009-2019 }\end{array}$ \\
\hline$A C$ & 501 & 574 & 578 & 503 & 467 & $-7 \%$ \\
\hline AL & 474 & 574 & 636 & 591 & 591 & $25 \%$ \\
\hline AM & 805 & 979 & 1.180 & 1.082 & 1.163 & $44 \%$ \\
\hline AP & 370 & 463 & 535 & 580 & 550 & $49 \%$ \\
\hline BA & 2.515 & 2.684 & 2.694 & 3.167 & 3.191 & $27 \%$ \\
\hline CE & 932 & 1.295 & 1.141 & 1.350 & 1.466 & $57 \%$ \\
\hline DF & 1.772 & 2.131 & 2.241 & 2.011 & 2.072 & $17 \%$ \\
\hline ES & 796 & 1.020 & 937 & 720 & 671 & $-16 \%$ \\
\hline $\mathrm{GO}$ & 1.806 & 2.272 & 2.266 & 2.132 & 2.177 & $21 \%$ \\
\hline MA & 1.205 & 1.632 & 1.473 & 1.451 & 1.464 & $22 \%$ \\
\hline MG & 4.929 & 5.708 & 6.697 & 5.573 & 6.179 & $25 \%$ \\
\hline MS & 954 & 1.083 & 1.054 & 912 & 1.000 & $5 \%$ \\
\hline MT & 948 & 1.383 & 1.181 & 1.194 & 1.657 & $75 \%$ \\
\hline PA & 1.651 & 2.379 & 2.170 & 2.194 & 1.690 & $2 \%$ \\
\hline PB & 665 & 992 & 962 & 683 & 735 & $11 \%$ \\
\hline PE & 1.552 & 1.654 & 1.653 & 1.887 & 1.832 & $18 \%$ \\
\hline $\mathrm{PI}$ & 637 & 571 & 570 & 764 & 794 & $25 \%$ \\
\hline PR & 3.086 & 3.862 & 4.460 & 3.535 & 3.724 & $21 \%$ \\
\hline RJ & 2.629 & 3.585 & 3.138 & 2.724 & 2.288 & $-13 \%$ \\
\hline $\mathrm{RN}$ & 717 & 919 & 888 & 683 & 757 & $6 \%$ \\
\hline RO & 469 & 579 & 651 & 575 & 600 & $28 \%$ \\
\hline $\mathrm{RR}$ & 315 & 366 & 413 & 385 & 406 & $29 \%$ \\
\hline RS & 3.146 & 3.229 & 3.999 & 3.012 & 2.868 & $-9 \%$ \\
\hline SC & 1.660 & 2.070 & 1.987 & 1.943 & 1.970 & $19 \%$ \\
\hline SE & 509 & 688 & 634 & 566 & 610 & $20 \%$ \\
\hline $\mathrm{SP}$ & 12.050 & 13.442 & 14.550 & 11.479 & 10.757 & $-11 \%$ \\
\hline TO & 575 & 729 & 798 & 751 & 584 & $2 \%$ \\
\hline Totais & 47.667 & 56.861 & 59.488 & 52.445 & 52.260 & $10 \%$ \\
\hline
\end{tabular}

Fonte: Elaboração dos autores com base em dados de Brasil (2020d).

Os dados da Tabela 6 mostram que o total das despesas com remuneração pagas com recursos do Fundeb pelos governos estaduais foi ampliado em 10\% de 2009 a 2019, mas com variações bem diversificadas entre eles.

Assim, é possível observar que, em cinco estados (AC, ES, RJ, RS e SP), a variação foi negativa e, dentre aqueles que apresentaram crescimento, os percentuais foram também diferentes.

A confluência de várias medidas, tais como a determinação de que o PSPN corresponda ao vencimento, o fluxo significativo de transferências de receitas do Fundeb aos governos municipais e a retração na arrecadação de impostos (PERES; TIBURCIO, 2017), podem ter 
Contribuições para um Balanço do Fundeb

contribuído no comprometimento importante dos recursos do Fundeb com remuneração dos professores das redes estaduais, como mostram os dados da Tabela 7.

Tabela 7 - Proporção das despesas com o pagamento da remuneração dos profissionais do magistério sobre a receita recebido do Fundeb, 2009/2012/2014/2016/2019

\begin{tabular}{|c|c|c|c|c|c|c|}
\hline Estados & 2009 & 2010 & 2012 & 2014 & 2016 & 2019 \\
\hline $\mathrm{AC}$ & $94 \%$ & $90 \%$ & $93 \%$ & $92 \%$ & $79 \%$ & $69 \%$ \\
\hline $\mathrm{AL}$ & $75 \%$ & $69 \%$ & $70 \%$ & $81 \%$ & $81 \%$ & $82 \%$ \\
\hline AM & $72 \%$ & $62 \%$ & $60 \%$ & $69 \%$ & $71 \%$ & $63 \%$ \\
\hline AP & $66 \%$ & $65 \%$ & $70 \%$ & $82 \%$ & $97 \%$ & $94 \%$ \\
\hline $\mathrm{BA}$ & $85 \%$ & $83 \%$ & $70 \%$ & $75 \%$ & $96 \%$ & $96 \%$ \\
\hline $\mathrm{CE}$ & $68 \%$ & $66 \%$ & $78 \%$ & $66 \%$ & $81 \%$ & $87 \%$ \\
\hline DF & $86 \%$ & $91 \%$ & $96 \%$ & $99 \%$ & $94 \%$ & $97 \%$ \\
\hline ES & $77 \%$ & $90 \%$ & $87 \%$ & $81 \%$ & $73 \%$ & $65 \%$ \\
\hline $\mathrm{GO}$ & $97 \%$ & $100 \%$ & $98 \%$ & $100 \%$ & $100 \%$ & $101 \%$ \\
\hline MA & $91 \%$ & $95 \%$ & $95 \%$ & $100 \%$ & $95 \%$ & $98 \%$ \\
\hline MG & $72 \%$ & $69 \%$ & $72 \%$ & $81 \%$ & $74 \%$ & $77 \%$ \\
\hline MS & $99 \%$ & $99 \%$ & $100 \%$ & $95 \%$ & $89 \%$ & $89 \%$ \\
\hline MT & $73 \%$ & $73 \%$ & $95 \%$ & $73 \%$ & $72 \%$ & $96 \%$ \\
\hline $\mathrm{PA}$ & $101 \%$ & $87 \%$ & $100 \%$ & $94 \%$ & $96 \%$ & $70 \%$ \\
\hline PB & $66 \%$ & $63 \%$ & $85 \%$ & $82 \%$ & $62 \%$ & $68 \%$ \\
\hline PE & $68 \%$ & $71 \%$ & $62 \%$ & $63 \%$ & $82 \%$ & $81 \%$ \\
\hline PI & $81 \%$ & $79 \%$ & $62 \%$ & $67 \%$ & $92 \%$ & $78 \%$ \\
\hline PR & $81 \%$ & $86 \%$ & $87 \%$ & $94 \%$ & $78 \%$ & $82 \%$ \\
\hline $\mathrm{RJ}$ & $78 \%$ & $88 \%$ & $98 \%$ & $91 \%$ & $96 \%$ & $84 \%$ \\
\hline $\mathrm{RN}$ & $83 \%$ & $78 \%$ & $90 \%$ & $102 \%$ & $72 \%$ & $84 \%$ \\
\hline $\mathrm{RO}$ & $64 \%$ & $76 \%$ & $69 \%$ & $75 \%$ & $69 \%$ & $71 \%$ \\
\hline RR & $74 \%$ & $74 \%$ & $85 \%$ & $92 \%$ & $88 \%$ & $90 \%$ \\
\hline $\mathrm{RS}$ & $74 \%$ & $69 \%$ & $70 \%$ & $82 \%$ & $65 \%$ & $65 \%$ \\
\hline $\mathrm{SC}$ & $74 \%$ & $69 \%$ & $82 \%$ & $78 \%$ & $83 \%$ & $77 \%$ \\
\hline $\mathrm{SE}$ & $80 \%$ & $83 \%$ & $93 \%$ & $87 \%$ & $83 \%$ & $89 \%$ \\
\hline SP & $64 \%$ & $63 \%$ & $64 \%$ & $70 \%$ & $66 \%$ & $62 \%$ \\
\hline TO & $75 \%$ & $87 \%$ & $82 \%$ & $88 \%$ & $88 \%$ & $73 \%$ \\
\hline Totais & $77 \%$ & $76 \%$ & $79 \%$ & $80 \%$ & $78 \%$ & $76 \%$ \\
\hline
\end{tabular}

Fonte: Elaboração dos autores com base em dados de Brasil (2020d).

Os dados evidenciam que, no período de 2009 a 2019, alguns estados, de forma contínua ou não, chegaram a comprometer de 90 a 100\% dos recursos do Fundeb com o pagamento dos profissionais do magistério, ou seja, bem acima do estipulado no art. 22 da Lei 11.494/2007 (BRASIL, 2007a).

Chama a atenção o fato de que, em vários estados, o comprometido das receitas do Fundeb com o pagamento de remuneração dos professores foi ampliado nos últimos anos da série histórica, de modo que, em 2019 , quinze estados destinaram mais de $80 \%$ das receitas para esse fim. Trata-se de opção governamental no uso dos recursos do Fundo, visto que a Lei que o regulamenta estabelece o mínimo. Importa destacar que, entre os quinze estados que se encontravam nessa condição, em 2019, apenas cinco (AL, BA, CE, MA, PE) receberam complementação da União. 
Contribuições para um Balanço do Fundeb

\section{O Fundeb e as formas de contratação docente}

A forma de contratação dos professores da educação básica das redes públicas de ensino é aspecto importante para a valorização docente, além de ser fundamental para um bom funcionamento das redes de ensino e contribuir para a qualidade da educação. Assim como os demais servidores públicos das distintas esferas administrativas, desde a Constituição Federal de 1934, o ingresso dos professores no serviço público deve ser por meio de concurso público.

Complementa a legislação federal em vigor, que trata da forma de ingresso dos professores nas redes públicas de ensino, o Plano Nacional de Educação, Lei no 13.005/2014 (BRASIL, 2014) (PNE 2014-2024), cuja estratégia 18.1, da Meta 18, propõe que ao menos $90 \%$ dos profissionais do magistério e $50 \%$ dos profissionais da educação não docentes sejam ocupantes de cargos efetivos até o início do terceiro ano de vigência do Plano, isto é, 2017.

No "Relatório do $2^{\circ}$ Ciclo de Monitoramento das Metas do Plano Nacional de Educação - 2018" (BRASIL, 2018), não há registro de acompanhamento da realização da estratégia 18.1, ou seja, apesar do prazo para a realização da referida estratégia ter terminado, o INEP não fez tal levantamento junto aos entes federados ou não o publicou.

Com a finalidade de verificar se a estratégia 18.1 tem sido cumprida nas redes públicas estaduais de ensino, apresentam-se, na Tabela 8 , o número de professores por tipo de vínculo e a variação percentual no período de 2011 a 2019.

Tabela 8 - Número de professores por tipo de vínculo, dependência administrativa estadual, 2011 a 2019

\begin{tabular}{lcccccccccc}
\hline \multicolumn{1}{c}{ Tipo de Vínculo } & 2011 & 2012 & 2013 & 2014 & 2015 & 2016 & 2017 & 2018 & 2019 & $\begin{array}{c}\text { Variação } \\
\text { no período }\end{array}$ \\
\hline Concursado/Efetivo/Estável & 475.919 & 504.204 & 505.439 & 498.732 & 473.287 & 455.006 & 436.202 & 403.289 & 393.902 & $-17 \%$ \\
Contrato temporário & 221.763 & 232.174 & 230.140 & 241.350 & 263.746 & 267.081 & 255.444 & 275.942 & 266.155 & $20 \%$ \\
Contrato terceirizado & 2.031 & 1.458 & 875 & 747 & 1.200 & 958 & 796 & 938 & 762 & $-62 \%$ \\
Contrato CLT & nd & 3.480 & 2.572 & 2.746 & 3.453 & 2.993 & 2.578 & 11.717 & 11.941 & $243 \%$ \\
\hline Total & $\mathbf{6 9 9 . 7 1 3}$ & $\mathbf{7 4 1 . 3 1 6}$ & $\mathbf{7 3 9 . 0 2 6}$ & $\mathbf{7 4 3 . 5 7 5}$ & $\mathbf{7 4 1 . 6 8 6}$ & $\mathbf{7 2 6 . 0 3 8}$ & $\mathbf{6 9 5 . 0 2 0}$ & $\mathbf{6 9 1 . 8 8 6}$ & $\mathbf{6 7 2 . 7 6 0}$ & $-4 \%$ \\
\hline
\end{tabular}

Fonte: Elaboração dos autores com base em dados de Brasil (2020e; 2020g).

O primeiro dado que chama a atenção na Tabela 8 é que houve pouca oscilação no número total de professores no período, pois sai de 699 mil em 2009, cresceu e estabilizou em cerca de 740 mil entre 2012 e 2015, declinando em 2016, com tendência de queda nos últimos três anos da série, atingindo 672 mil em 2019, com diminuição de $4 \%$ no número total no período. Observa-se também que, em relação aos professores com contrato temporário, a tendência foi de crescimento no período, enquanto, em relação aos efetivos/estáveis, foi de queda.

As categorias de contratos terceirizados e sob a Consolidação das Leis Trabalhistas (CLT) são residuais frente ao número de professores das redes estaduais de ensino. No caso dos terceirizados há oscilação, com tendência de queda no período enquanto a contratação de professores nas redes estaduais pela CLT apresentou variação, com aumento significativo 
Contribuições para um Balanço do Fundeb

nos dois últimos anos da série. Será interessante verificar em estudos futuros se isso se trata de uma questão pontual ou uma tendência, em tempos de mudanças substanciais na CLT, realizadas pela Lei $n^{\circ}$ 13.467/2017 (BRASIL, 2017).

Observa-se, a partir de 2014, ano de aprovação do atual PNE, início de queda no número de professores efetivos/estáveis em relação aos contratados temporariamente, que cresceu $20 \%$ no período de 2011 a 2019 , enquanto o número de efetivos/estáveis diminuiu $17 \%$.

Esses dados, ainda que referentes a um curto período, mostram que no último ano da série, dois anos após o término do prazo para o cumprimento da estratégia 18.1, as redes estaduais contavam com $59 \%$ de seus professores na condição de efetivos/estáveis, bastante distante dos 90\% previstos no PNE 2014-2024 (BRASIL, 2014). Isso se agrava pelo fato de a tendência ser de aumento da contratação temporária, ou seja, crescimento da precarização das relações de trabalho no que se refere à forma de contratação.

Além das condições de trabalho docente ainda mais precárias a que estes professores estão submetidos, tendo em vista que geralmente não fazem parte da carreira, essa forma de contratação, num percentual tão alto, $40 \%$ em 2019, desfavorece a formação de equipes de professores mais permanentes, elemento essencial para o desenvolvimento do projeto educativo das unidades escolares.

Estudos de Quibao Neto (2015), Santos (2016), Quibao Neto e Santos (2018) sobre os professores contratados na rede estadual paulista, a maior do País, indicam que essa forma de contratação se apresenta como uma estratégia da administração pública para a contenção de gastos com pagamento de pessoal, considerando que a categoria de professores é normalmente a mais numerosa entre os servidores públicos.

Num momento em que a tônica das discussões econômicas gira em torno das propostas de austeridade (ROSSI; DWECK; OLIVEIRA, 2018), consubstanciadas, até o momento, na Emenda Constitucional $n^{\circ}$ 95/2016, que institui novo regime fiscal e na reforma da previdência, por meio da Emenda Constitucional $n^{\circ}$ 103/2019, a tendência de aumento de contratação de professores por tempo determinado em detrimento da efetivação via concurso público, iniciada em 2014, de acordo com a série histórica apresentada, pode se intensificar. Como mostrou estudo de Amaral (2016) sobre a EC 95/2016, quando ainda era Proposta de Emenda Constitucional 241, a "PEC do fim do mundo", como ficou conhecida entre os pesquisadores que apontavam suas consequências nefastas para a garantia dos direitos sociais, entre eles a educação, o PNE 2014-2024 dificilmente será implementado.

\section{Breves considerações para finalizar}

Em relação ao sentido de municipalização usado neste artigo, observou-se que, a despeito da redução absoluta do atendimento das matrículas municipais no período de 2007 a 2019 - que também ocorreu nas demais dependências aqui analisadas -, houve um aumento percentual do atendimento municipal nas matrículas em relação ao percentual estadual, impactando a redistribuição dos recursos dos fundos, permitindo afirmar que ocorreu uma espécie de processo de municipalização em decorrência da redistribuição dos recursos do Fundeb.

Nesse sentido, a dimensão da municipalização do ensino evidencia um aspecto da desigualdade que parece ser uma tendência estrutural da política de fundos, pois é de se 
lembrar que são os municípios os entes federativos com os maiores encargos para atendimento de políticas públicas de diversos setores, entre eles a educação, enquanto são os mais frágeis em termos de arrecadação própria e de transferências de tributos. O impacto para as políticas educacionais, com exceção das capitais e daqueles com maior arrecadação, é relevante. São eles que, em geral, pagam menores remunerações aos docentes, têm carreiras pouco atrativas e as condições de trabalho mais precarizadas (GATTI; BARRETO, 2009; PINTO, 2000).

$\mathrm{Na}$ dimensão do valor do custo aluno ano e do valor do PSPN, observou-se que esses valores aumentaram de acordo com o cenário econômico do período em tela. Certamente, o valor por aluno e o PSPN estiveram em larga medida determinados pela interseção da política educacional com a política econômica da União em cada ente federativo, pois se constatou que em 21 estados houve variação positiva tanto nas receitas do Fundeb quanto nas despesas com remuneração dos profissionais do magistério, em média, em 10\%. Além disso, em todos eles os valores destinados a essa rubrica foram percentualmente acima do mínimo estipulado em Lei. Em 2019, 15 estados destinaram mais de $80 \%$ das receitas para esse fim e, dentre eles, apenas cinco ( $\mathrm{AL}, \mathrm{BA}, \mathrm{CE}, \mathrm{MA}, \mathrm{PE}$ ) receberam complementação da União. Desse modo, os dados sinalizam para o limite do volume disponibilizado pelos fundos estaduais na efetivação de uma política de valorização do magistério por meio da remuneração. De acordo com dados da Confederação Nacional dos Trabalhadores em Educação (CNTE), em abril de 2019, dos 27 estados, 15 pagaram o Piso, 8 não pagaram e 4 pagaram proporcionalmente à jornada do professor.

$\mathrm{Na}$ dimensão dos vínculos de trabalho docente observou-se que, mesmo tendo em vista a redução do número professores com vínculos efetivos/estáveis pari passu ao aumento do número do vínculo de contratos temporários, pode-se supor que os aumentos reais no valor aluno ano e, por conseguinte, no PSPN, foram absorvidos pelos governos estaduais de forma negativa, contrariando a expectativa de valorização do magistério que a formalidade da lei visava garantir. Ou seja, na medida em que o cumprimento dessa legislação significaria elevar substancialmente a remuneração docente e as despesas com a folha de pagamento do magistério em particular e, consequentemente, as despesas com educação, constatou-se, ao contrário, que o movimento observado nos tipos de vínculos dos professores estaduais atenuou e até anulou o esperado impacto positivo na valorização do magistério, avançando inclusive na precarização.

A aprovação da EC n. 95/2016 inaugurou um contexto de forte austeridade fiscal, ao congelar os gastos públicos federais por vinte anos, (re)colocando, desde então, velhos e novos desafios aos sistemas de ensino do País. Ainda que políticas do ciclo governamental imediatamente anterior, como o Fundeb e o PSPN, permanecessem em desenvolvimento no novo contexto, ao qual os entes federativos tenham que se adequar, percebe-se, pelos dados levantados para este artigo, que a tendência principal que parece estar se materializando é o de aprofundamento das desigualdades e das assimetrias regionais, com graves consequências para o setor educacional. Realça essa constatação o fato de que o Fundeb foi aprovado em caráter de transitoriedade e seu prazo finda-se em 2020.

A redistribuição de recursos que a política de fundos inaugurou na segunda metade dos anos de 1990 é promissora e necessária, em face da tendência crescente de responsabilização dos municípios na execução das políticas educacionais. Todavia, a 
redistribuição dos recursos do Fundeb apresenta limites decorrentes das diferentes capacidades fiscais dos entes federados com rebatimentos importantes no financiamento da educação, que, ainda, não foi capaz de romper com as históricas desigualdades educacionais. Isso poderia ser resolvido, em parte, se a União exercesse de fato a função redistributiva e supletiva de modo que o Fundeb propiciasse recursos necessários para ampliar o atendimento em condições adequadas de oferta e de valorização dos profissionais da educação por meio de uma política autêntica de remuneração, o que, apesar dos avanços, ainda não se concretizou.

Apesar de o estudo ter realçado aspectos negativos nas dimensões examinadas, esses emergem nos anos finais da série histórica. Em seu início e em grande parte de sua vigência, Fundeb e PSPN implicaram ganhos reais e substanciais para a remuneração e valorização do magistério público da educação básica. Atesta essa afirmação a pesquisa sobre a remuneração dos professores de escolas públicas de educação básica no contexto do Fundeb e do PSPN com recorte histórico de investigação entre 2006 e 2014 e a participação ativa dos autores do presente estudo, que identificou esses ganhos reais em 10 estados e suas capitais (BASSI; FERNANDES; ROLIM 2018). Não por menos, esses e outros resultados positivos consolidados deram ensejo à configuração de um novo Fundeb, permanente e com um aporte maior de recursos da União a partir de 2021. No momento da elaboração deste artigo uma Proposta de Emenda Constitucional do novo Fundeb (PEC $\left.n^{\circ} 15 / 2015\right)$ encontrava-se em ponto de iminente aprovação no congresso nacional. Além da aprovação da PEC mencionada, o esforço político é pela mudança imediata do contexto de austeridade e política fiscal restritiva para um contexto de crescimento e desenvolvimento econômico. Desse modo, políticas públicas como as abordadas aqui cumprirão efetivamente o seu objetivo de valorização e de remuneração do magistério.

\section{Referências}

AMARAL, N. C. do. PEC 241/55: a "morte" do PNE (2014-2024) e o poder de diminuição dos recursos educacionais. Revista Brasileira de Política e Administração Educacional, v. 38, n. 3, p. 653-673, set./dez. 2016.

AMARAL, N. C. do. Com a PEC 241/55 (EC 95) haverá prioridade para cumprir as metas do PNE (2014-2024)? Revista Brasileira de Educação, Rio de Janeiro, v. 22, n. 71, e227145, 2017. Disponível em: <http://www.scielo.br/pdf/rbedu/v22n71/1809-449X-rbedu-s141324782017227145.pdf>. Acesso em: 12 out. 2017.

ARAÚJO, L. O federalismo brasileiro e a aprovação da Emenda Constitucional n. 53 de 2006. Fineduca - Revista de Financiamento da Educação, Porto Alegre, v. 1, n. 5, p. 1-13, 2011.

ARELARO, L. R. G. A municipalização do ensino no Estado de São Paulo: antecedentes históricos e tendências. In: OLIVEIRA, C. et al. Municipalização do ensino no Brasil. Belo Horizonte: Autêntica, 1999. p. 61-90.

BASSI, M. E.; FERNANDES, M. D. E.; ROLIM, R. M. G. (Org.). Remuneração de professores da educação básica das redes estaduais de ensino no contexto do Fundeb e do PSPN. Curitiba: Appris, 2018. 
Contribuições para um Balanço do Fundeb

BASSI, M. E.; GIL, J. A municipalização do ensino no Estado de São Paulo: impactos do Fundef no atendimento municipal. São Paulo: Ação Educativa, 1999.

BRASIL. Constituição da República Federativa do Brasil de 1988. Diário Oficial da União, Brasília, 1988. Disponível em: <http://www.planalto.gov.br/ccivil_03/constituicao/constitu icao.htm>. Acesso em: 20 mar. 2020.

BRASIL. Lei Complementar n 87, de 13 de setembro de 1996. Dispõe sobre o imposto dos Estados e do Distrito Federal sobre operações relativas à circulação de mercadorias e sobre prestações de serviços de transporte interestadual e intermunicipal e de comunicação, e dá outras providências. Diário Oficial da União, Brasília, 1996a. Disponível em: <http://www.planalto.gov.br/ccivil_03/leis/lcp/Lcp87.htm>. Acesso em: 29 abr. 2020.

BRASIL. Lei no 9.394, de 20 de dezembro de 1996. Diário Oficial da União, Brasília, 1996b. Disponível em: <http://www.planalto.gov.br/ccivil_03/leis/19394.htm>. Acesso em: 20 mar. 2020.

BRASIL. Emenda Constitucional $n^{\circ} 53$, de 19 de dezembro de 2006. Diário Oficial da União, Brasília, 2006. Disponível em: <http://www.planalto.gov.br/ccivil_03/constituicao/E mendas/Emc/emc53.htm>. Acesso em: 20 mar. 2020.

BRASIL. Lei $n^{0}$ 11.494, de 20 de junho de 2007. Diário Oficial da União, Brasília, 2007. Disponível em: <http://www.planalto.gov.br/ccivil_03/_ato2007-2010/2007/lei/l11494.htm>. Acesso em: 20 mar. 2020.

BRASIL. Lei $n^{\circ} 11.738$, de 16 de julho de 2008. Regulamenta a alínea "e" do inciso III do caput do art. 60 do Ato das Disposições Constitucionais Transitórias, para instituir o Piso salarial profissional nacional para os profissionais do magistério público da educação básica. Diário Oficial da União, Brasília, 2008a. Disponível em: <http://www.planalto.gov.br/ccivil_03/ ato2007-2010/2008/lei//11738.htm>. Acesso em: 8 maio 2020.

BRASIL. Supremo Tribunal Federal. Decisão Tribunal Pleno, 17 /12/ 2008. Acompanhamento Processual da ADI 4167 - Ação Direta de Inconstitucionalidade. Brasília, 2008b. Disponível em: <http://portal.stf.jus.br/processos/detalhe.asp?incidente=2645108>. Acesso em: 07 mar. 2020.

BRASIL. Supremo Tribunal Federal. STF decide que o Piso nacional dos professores é válido desde abril de 2011. Brasília, 2013. Disponível em: <http://www.stf.jus.br/portal/cms/ verNoticiaDetalhe.asp?idConteudo=232067>. Acesso em: 12 mar. 2020.

BRASIL. Emenda Constitucional $n^{\circ} 95$, de 15 de dezembro de 2016. Institui novo regime fiscal. Diário Oficial da União, Brasília, 2016. Disponível em: <http://www.planalto.gov.br/ccivil_03/ constituicao/Emendas/Emc/emc95.htm>. Acesso em: 20 mar. 2020.

BRASIL. Lei $n^{\circ}$ 13.467, de 13 de julho de 2017. Altera a Consolidação das Leis Trabalhistas (CLT). Diário Oficial da União, Brasília, 2017. Disponível em: <http://www.planalto.gov.br/ ccivil_03/_ato2015-2018/2017/lei//13467.htm>. Acesso em: 20 mar. 2020.

BRASIL. Instituto Nacional de Estudos e Pesquisas Educacionais Anísio Teixeira (Inep). Relatório do $2^{\circ}$ ciclo de monitoramento das metas do Plano Nacional de Educação 2018. Brasília-DF, 2018. 
Contribuições para um Balanço do Fundeb

BRASIL. Emenda Constitucional $n^{\circ}$ 103, de 12 de novembro de 2019. Altera o sistema de previdência social. Diário Oficial da União, Brasília, 2019a. Disponível em: <http://www .planalto.gov.br/ccivil_03/constituicao/emendas/emc/emc103.htm>. Acesso em: 20 mar. 2020.

BRASIL. Senado Federal. Atividades Legislativas. Proposta de Emenda à Constituição $\mathbf{n}^{\circ}$ 65, de 2019. Brasília, 2019b. Disponível em: <https://www25.senado.leg.br/web/atividade/ materias/-/materia/136606>. Acesso em: 27 maio 2020.

BRASIL. Ministério da Economia. Tesouro Nacional. Fundeb. Brasília, 2020a. Disponível em: $<$ http://www.tesouro.fazenda.gov.br/transferencias-constitucionais-e-legais>. Acesso em: 03 mar. 2020.

BRASIL. Ministério da Educação. Piso salarial profissional nacional. Brasília, 2020b. Disponível em: <http://portal.mec.gov.br/pisoPiso-salarial-de-professores>. Acesso em: 08 abr. 2020.

BRASIL. Fundo Nacional de Desenvolvimento da Educação. Dados estatísticos. Valor aluno ano e receita anual prevista - 2009 a 2019. 2020c. Disponível em: https://www.fnde.gov.br/index.php/financiamento/fundeb/area-para-gestores/dadosestatisticos. Acesso em: 06 mar. 2020.

BRASIL. Fundo Nacional de Desenvolvimento da Educação. SIOPE. Relatórios estaduais. Demonstrativo Fundef/Fundeb para os anos de 2009 a 2019. Brasília, 2020d. Disponível em: <https://www.fnde.gov.br/siope/demonstrativoFundefEstadual.do>. Acesso em: 06 mar. 2020.

BRASIL. Instituto Nacional de Estudos e Pesquisas Educacionais Anísio Teixeira. Sinopses estatísticas da educação básica 2009 a 2019. Brasília, 2020e. Disponível em: <http://portal.inep.gov.br/web/guest/sinopses-estatisticas-da-educacao-basica>. Acesso em: 03 mar. 2020.

BRASIL. Senado Federal. Manter o Fundeb e garantir recursos são desafios do Congresso em 2020. Brasília, 2020f. Disponível em: <https://www12. senado.leg.br/noticias/materias/2020/01/06/manter-o-fundeb-e-garantir-recursos-saodesafios-do-congresso-em-2020>. Acesso em: 07 jan. 2020.

BRASIL. Ministério da Educação. Universidade Federal do Paraná. Laboratório de Dados Educacionais. Brasília, 2020g. Disponível em: <https://dadoseducacionais.c3sl.ufpr.br/\# /indicadores/docentes>. Acesso em: 08 abr. 2020.

BRASIL. Supremo Tribunal Federal. Imprensa. Lei que reserva 1/3 da carga horária do magistério para atividades extraclasse é constitucional. Brasília, 2020h. Disponível em: $<$ http://portal.stf.jus.br/noticias/verNoticiaDetalhe.asp?idConteudo=444594\&ori=1>. Acesso em: 8 jun. 2020.

CAMARGO, R. B. de; OLIVEIRA, R. P. de; MANSANO FILHO, R. Tendências das Matrículas no Ensino Fundamental Regular no Brasil. In: OLIVEIRA, C. et al. Municipalização do ensino no Brasil. Belo Horizonte: Autêntica, 1999. p. 37-60.

CNTE. Confederação Nacional dos Trabalhadores em Educação. Saiba quais estados brasileiros não respeitam a Lei do PisoPiso. Brasília, 2019. Disponível em: <https://www. cnte.org.br/index.php/menu/tabela-salarial>. Acesso em: 4 maio 2020. 
Contribuições para um Balanço do Fundeb

DIEESE. Departamento Intersindical de Estudos e Estatísticas. Nota Técnica. O Fundeb e o financiamento público da educação. n. 7. São Paulo, out. 2005.

FINEDUCA. Associação Nacional de Pesquisa em Financiamento da Educação. Por um Fundeb mais justo e com maior compromisso da União! São Paulo: 2020. Disponível em: $<$ https://fineduca.org.br/wp-content/uploads/2020/03/Fineduca_Nota_Por-um-Fundeb-maisjusto_01.03.2020.pdf>. Acesso em: 27 maio 2020.

FONSECA, F. Impactos do neoliberalismo ao estado de bem-estar e à democracia: Uma análise conceitual e empírica. GIGAPP Estudios Working Papers, v. 6, n. 117, p. 114-130, 2019. Disponível em: <https://pesquisa-eaesp.fgv.br/sites/gvpesquisa.fgv.br/files/arquivos/ 141-texto_del_arti_culo-523-1-10-20190416.pdf>. Acesso em: 27 mai. 2020.

GATTI, B. A.; BARRETO, E. S. de S. Professores do Brasil: impasses e desafios. Brasília: UNESCO, 2009.

MARTINS, A. M.; OLIVEIRA, C. de; BUENO, M. S. S. (Org.). Descentralização do Estado e municipalização do ensino: problemas e perspectivas. Rio de Janeiro: DP\&A, 2004.

PERES, U. D.; TIBÚRCIO, R. Pesquisa sobre Financiamento da Educação no Brasil Cenário das principais receitas brasileiras. CONSED, janeiro de 2017. Disponível em: <http://www.consed.org.br/consed/gt-financiamento/documentos>. Acesso em: 03 mar. 2018.

QUIBAO NETO, J. Docentes não concursados na Rede Estadual de Ensino de São Paulo: ordenamento jurídico, perfil e remuneração. 2015. Dissertação (Mestrado em Educação) Faculdade de Filosofia, Ciências e Letras de Ribeirão Preto da Universidade de São Paulo, Ribeirão Preto, 2015.

QUIBAO NETO, J.; SANTOS, J. B. S. O contrato temporário como estratégia de administração pública na rede estadual de ensino de São Paulo. In: ENCONTRO ANAUAL DA FINEDUCA, 6, 2018, Campinas. Anais... Campinas: FINEDUCA, 2018.

ROCHA, C. "Imposto é Roubo!" A Formação de um Contrapúblico ultraliberal e os Protestos PróImpeachment de Dilma Rousseff. DADOS, Rio de Janeiro, v. 62, n. 3, p. 1-42, 2019. Disponível em: <https://www.scielo.br/pdf/dados/v62n3/0011-5258-dados-62-3-e20190076.pdf>. Acesso em: 27 maio 2020.

ROSSI, P.; DWECK, E.; OLIVEIRA, A. L. M de. Economia para poucos: impactos sociais da austeridade e alternativas para o Brasil. São Paulo: Autonomia Libertária, 2018.

SANTOS, J. B. S. dos. Professores temporários da rede estadual de São Paulo: análise da política de pessoal da perspectiva orçamentária. 2016. Dissertação (Mestrado em Educação) - Escola de Filosofia, Letras e Ciências Humanas, Universidade Federal de São Paulo, Guarulhos, 2016.

SONOBE, A. K.; PINTO, J. M. de R.; RIBEIRO, J. M. C. Análise da evolução dos gastos por aluno em alguns estados brasileiros, suas respectivas capitais e sua relação com o Fundeb. Revista Brasileira de Política e Administração da Educação, Goiânia, v. 34, n. 2, p. 395-411, set. 2018. Disponível em: <https://seer.ufrgs.br/rbpae/article/view/86366/49648>. Acesso em: 23 abr. 2020. 
Contribuições para um Balanço do Fundeb

Márcia Aparecida Jacomini é doutora em Educação pela Faculdade de Educação da Universidade de São Paulo (2008). Pós-doutorado pela Faculdade de Educação da Universidade de São Paulo (2018), com estágio na Fondazione Istituto Gramsci, Roma, Itália. Graduada em Pedagogia com especialização em psicopedagogia pela PUC-SP (1990-1997). Professora Associada de graduação e pós-graduação do Departamento de Educação da Escola de Filosofia, Letras e Ciências Humanas da Universidade Federal de São Paulo (Unifesp) - Campus Guarulhos.

ORCID: http://orcid.org/0000-0002-1825-0097

E-mail: jacominimarcia@gmail.com

Marcos Edgar Bassi é professor da Universidade Federal de Santa Catarina (UFSC), credenciado ao Programa de Pós-Graduação em Educação/UFSC. Tem desenvolvido pesquisa nos temas da política educacional e do financiamento da educação. Bacharel em Ciências Econômicas pela Universidade Municipal de São Caetano do Sul (IMES). Mestrado e Doutorado realizados no Programa de Estudos Pós-Graduados em Educação: História, Política, Sociedade, da Pontifícia Universidade Católica de São Paulo (PUC-SP). Estágio PósDoutoral realizado na Faculdade de Educação da Universidade de São Paulo (FEUSP).

ORCID: http://orcid.org/0000-0002-1825-0097

E-mail: marco.e.bassi@gmail.com

Maria Dilnéia Espíndola Fernandes é professora Visitante da Universidade Federal de Mato Grosso do Sul (UFMS). Credenciada no Programa de Pós-Graduação em Educação, na Linha de Pesquisa História, Políticas e Educação. Professora Titular da Universidade Federal de Mato Grosso do Sul. Realizou Estágio Pós-Doutoral em Educação na Universidade de São Paulo (FE-USP) em 2013. Graduação em Pedagogia pela Universidade Federal de Mato Grosso do Sul (1987). Mestre em Educação pela Universidade Federal de Mato Grosso do Sul (1996). Doutora em Educação pela Universidade Estadual de Campinas (2001).

ORCID: http://orcid.org/0000-0002-1825-0097

E-mail: mdilneia@uol.com.br

Rosana Maria Gemaque Rolim é possui graduação em Pedagogia pela Universidade Federal do Pará (1987), Mestrado em Educação pela Pontifícia Universidade Católica do Rio de Janeiro (1995), Doutorado em Educação pela Universidade de São Paulo (2004)'e PósDoutorado em Educação pela Universidade de São Paulo (2013). Atualmente é professor Associado III da Universidade Federal do Pará, atuando na Graduação e Pós-Graduação.

ORCID: http://orcid.org/0000-0002-1825-0097

E-mail:rgemaque@uol.com.br

Rubens Barbosa de Camargo é professor Livre-Docente. Desde 1998 foi Professor Doutor do Departamento de Administração Escolar e Economia da Educação (EDA) da Faculdade de Educação da Universidade de São Paulo (Feusp).

ORCID: http://orcid.org/0000-0002-1988-2934

E-mail: rubensbc@usp.br 


\section{Editores do volume 10}

Márcia Aparecida Jacomini - Universidade Federal de São Paulo, Brasil

José Marcelino de Rezende Pinto - Universidade de São Paulo, Brasil

\section{Comitê Editorial}

Nalú Farenzena - Universidade Federal do Rio Grande do Sul, Brasil

Juca Gil - Universidade Federal do Rio Grande do Sul, Brasil

Theresa Adrião - Universidade Estadual de Campinas, Brasil

Ângelo Ricardo de Souza - Universidade Federal do Paraná, Brasil

\section{Conselho Editorial}

\section{Alejandro Morduchowicz}

Universidad Pedagógica, Provincia de Buenos Aires, Argentina

Andréa Barbosa Gouveia

Universidade Federal do Paraná, Brasil

Fernanda Saforcada

Universidade de Buenos Aires, Argentina

Jacques Velloso

Universidade de Brasília, Brasil

João Monlevade

Senado Federal, Brasil

Jorge Abrahão de Castro

Instituto de Pesquisa Econômica Aplicada / IPEA, Brasil

Lisete Regina Gomes Arelaro

Universidade de São Paulo, Brasil

Luis Carlos Sales

Universidade Federal do Piauí, Brasil

Luiz de Sousa Junior

Universidade Federal da Paraíba, Brasil

Luiz Fernandes Dourado

Universidade Federal de Goiás, Brasil

Magna França

Universidade Federal do Rio Grande do Norte, Brasil

Marcos Edgar Bassi

Universidade Federal de Santa Catarina, Brasil

Maria Angélica Pedra Minhoto

Universidade Federal de São Paulo, Brasil

Maria Beatriz Luce

Universidade Federal do Rio Grande do Sul, Brasil

Maria Dilnéia Espíndola Fernandes

Universidade Federal de Mato Grosso do Sul, Brasil

Nelson Cardoso do Amaral

Universidade Federal de Goiás, Brasil

Nicholas Davies

Universidade Federal Fluminense, Brasil

Robert E. Verhine

Universidade Federal da Bahia, Brasil

Romualdo Portela de Oliveira

Universidade de São Paulo, Brasil

Rosana Gemaque Rolim

Universidade Federal do Pará, Brasil

Rubens Barbosa de Camargo

Universidade de São Paulo, Brasil

Theresa Adrião

Universidade Estadual de Campinas, Brasil

Tristan McCowan

University of London, Reino Unido

Vera Jacob

Universidade Federal do Pará, Brasil

Vera Peroni

Universidade Federal do Rio Grande do Sul, Brasil

Vitor Henrique Paro

Universidade de São Paulo, Brasil

\section{Equipe editorial}

Apoio ao Comitê Editorial: Caio Cabral da Silva

Diagramação, Revisão de português e normalização: Edson Leonel de Oliveira

Revisão de inglês: Sabrina Ferreira

Fineduca - Revista de Financiamento da Educação

Associação Nacional de Pesquisa em

Financiamento da Educação

e-mail: revista.fineduca@gmail.com | site: http://seer.ufrgs.br/fineduca 